\title{
MONITORING HEART RATE DAN SATURASI OKSIGEN MELALUI SMARTPHONE
}

\author{
Ary Sulistyo Utomo \\ Teknik Elektro Medik \\ Akademi Teknik Elektro Medik \\ Email: ary.utomo@gmail.com \\ Erda Hermono Puspo Negoro \\ Teknik Elektro Medik \\ Akademi Teknik Elektro Medik \\ Mohamad Sofie \\ Teknik Elektro Medik \\ Akademi Teknik Elektro Medik
}

\begin{abstract}
ABSTRAK
Pada tubuh manusia terdapat beberapa tanda vital yang dapat mencerminkan indikasi dari kondisi kesehatan seseorang diantaranya yaitu tekanan darah, respirasi, denyut nadi dan suhu tubuh. Pada saat kondisi pasien dalam keadaan sakit parah sehingga berada pada ruang ICU maka diperlukan suatu pemantaunya yang dapat dipatau setiap saat dan kapanpun. Sehingga keluarga pasien dapat membantu pemantau tersebut, maka peneliti membuat alat monitoring heart rate dan saturasi oksigen yang dapat dimonitoring melalui smartphone. Pembuatan alat ini menggunakan sistem IoT (Internet of Things), dimana alat ini menggunakan sensor yang digunakan yaitu sensor heart rate dan sensor SPO2 MAX 30100, serta mikrokontroller Arduino nano dan ESP01 sebagai pengolah data dan koneksi Wi-Fi. Data tanda vital akan ditampilkan di aplikasi blynk pada smartphone android. Selisih pembacaan nilai heart rate dan saturasi oksigen pada alat dan pasien monitor terbesar $0,8 \%$ untuk heart rate dan $1 \%$ untuk saturasi oksigen. Pengiriman data hasil pembacaan sensor heart rate dan saturasi oksigen berhasil dimonitoring secara langsung melalui smartphone.
\end{abstract}

Kata kunci: tanda vital; IoT; blynk; arduino nano.

\begin{abstract}
In the human body there are several vital signs that can reflect on a person's health condition which emits blood pressure, respiration, pulse and body temperature. When patients are seriously ill so that they are in the ICU, monitoring is needed that can be monitored at any time and at any time. So that the patient's family can help the monitor, the researcher makes a heart rate reading and oxygen saturation tool that can be monitored via a smartphone. Making this tool uses the IoT (Internet of Things) system, where the device uses sensors that are used namely the heart rate sensor and SPO2 MAX 30100 sensor, and the Arduino nano and ESPO1 microcontrollers as data processing and Wi-Fi connections. Vital data data will be displayed in the Blynk application on an Android smartphone. The difference in reading the heart rate and oxygen saturation of the device and monitor patients is the largest $0.8 \%$ for heart rate and $1 \%$ for oxygen saturation. Sending data from sensor heart rate and oxygen saturation readings are successfully monitored directly through a smartphone.
\end{abstract}

Keywords: vital signs; IoT, blynk; arduino nano.

\section{PENDAHULUAN}

Di dalam tubuh manusia terdapat beberapa tanda-tanda vital yang menunjukkan fungsi sangat penting bagi tubuh manusia. Tanda-tanda vital tersebut adalah nilai fungsi dari fisiologis manusia yang terdiri dari tekanan darah, suhu tubuh, saturasi oksigen, denyut nadi dan laju pernafasan. Tanda vital ini dapat digunakan sebagai indikasi bahwa seseorang dalam kondisi sehat ataupun dalam kondisi sedang sakit [1]. Salah satu tanda vital yaitu heart rate atau denyut jantung yaitu jumlah denyut jantung per satuan waktu yang dinyatakan permenit atau beat per menite (bpm) [2]. heart rate merupakan parameter kesehatan yang berhubungan dengan kesehatan sistem kardiovaskular manusia. Jumlah denyut jantung per menit dapat mencerminkan kondisi fisiologis seseorang, seperti kondisi aktifitas, stress dan mengantuk. Orang dewasa 
yang sedang dalam kondisi sehat dan sedang dalam beraktiftas normal denyut jantung atau nadi sekitar 60 s/d 100 deyut permenit [1]. Denyut jantung yang terlalu lambat disebut bradikardia, sedangkan denyut jantung yang terlalu cepar disebut takikardia. Dalam keadaan jantung yang normal dapat dibagi mejadi 4 bagian berdasarkan usia seseorang. Empat bagian tersebut dapat dilihat pada tabel 1 [3].

Tabel 1. Denyut jantung normal dikelompokkan berdasar empat kelompok usia

\begin{tabular}{cccc}
\hline $\begin{array}{c}\text { Usia } \\
\text { (Tahun) }\end{array}$ & $\begin{array}{c}\text { Bradikardia } \\
\text { (bpm) }\end{array}$ & $\begin{array}{c}\text { Normal } \\
(\text { bpm })\end{array}$ & $\begin{array}{c}\text { Takikardia } \\
(\text { bpm })\end{array}$ \\
\hline$<1$ & $<100$ & $100-160$ & $>160$ \\
$1-10$ & $<70$ & $70-120$ & $>120$ \\
$11-17$ & $<60$ & $60-100$ & $>100$ \\
$>17$ & $<60$ & $60-100$ & $>100$ \\
\hline
\end{tabular}

Berdasarkan pengalaman yang pernah dilakukan penulis pada saat berada di rumah sakit daerah kudus yang pada waktu itu salah satu keluarga penulis mengalami kondisi beberapa tanda vital harus di monitoring secara terus menerus yang berada di ruang ICU. Pada saat berada diruang tersebut keluarga tidak dapat memantau secara langsung, pemantau dilakukan oleh perawat jaga dengan menuliskan kondisi pasien secara manual di atas kertas besar yang berada di depan kamar atau bed pasien. Dari kejadian tersebut penulis melakukan penelitian membuat alat yang dapat memonitoring heart rate dan saturasi oksigen secara online yang dapat di monitor secara langsung dan terus menerus melalui smartphone. Pemantauan ini memanfaatkan IoT (Internet of Things). IoT (Internet of Things) adalah suatu jaringan menghubungkan suatu jaringan dari berbagai objek yang memiliki alamat IP (Internet Protokol) serta identitas yang sama, sehingga dapat berkomunikasi maupun bertukar informasi. Dengan sistem ini diharapkan keluarga pasien yang berada di luar ruang perawatan dapat ikut memantau kondisi dari tanda vital dari pasien yang sedang sakit.

Penelitan sebelumnya yang dilakukan oleh Ary sulistyo utomo dkk berasal dari Akademi Teknik Elektro Medik Semarang melakukan perancangan monitoring baby incubator sentral dengan komunikasi wireless dimana kondisi dari suhu dan kelembaban dari incubator dapat diamati secara jarak jauh[4], I Ketut Resika, F dkk pada tahun 2017 melakukan Perancangan Alat Pendeteksi Detak Jantung dengan hasilnya di kirim melalui SMS ke handphone[3], Fachrul Rozie pada 2016 melakukan rancang bangun alat monitoring jumlah denyut nadi atau jantung berbasis android dimana hasil dari pembacaan denyut nadi dapat dipantau melalui Handphone android[5], Herdi Fadillah dkk pada 2015 melakukan perancangan alat pemantau detak jantung, resistansi kulit dan suhu tubuh jarak jauh dimana hasil dari pemantauan dikirim di sebuah server [2], Nur Hudha Wijaya dkk pada tahun 2018 melakukan penelitian membuat alat ukur detak jantung dan suhu tubuh dilengkapi penyimpanan data dimana hasil dari pengukuran detak jantung di simpan sehingga kemudian hari data tersebut dapat dilihat kembali [6]. Indra prayogo dkk pada tahun 2017 membuat penelitian sistem monitoring denyut jantung dan suhu tubuh sebagai indikator level kesehatan pasien berbasis IoT(Internet Of Thing) dengan metode Fuzzy Logic menggunakan android dimana pembacaan dari denyut jantung dan suhu tubuh dapat menghasilkan hasil kondisi pasien dan data pembecaan dapat dilihat melalui smartphone ataupun dari komputer yang telah terhubung ke alat[7], Fuad Ughi pada tahun 2018 membuat penelitian proof-of-concept simulasi kadar saturasi oksigen untuk evaluasi pulse oximeter dimana hasil dari penelitian ini membuat simulasi kadar oksigen dengan mengatur intensitas cahaya light emitting diode (LED), untuk meniru penyerapan cahaya oleh darah pada pembuluh arteri [8]. Rifki yanuardi pada tahun 2016 melakukan rancang bangun pulse oximetry digital berbasis mikrokontroler atmega 16 dimana menghasilkan alat yang dapat menampilkan pembacaan kadar oksigen dalam darah [9]. Bandana Mallick pada tahun 2016 melakukan penelitian tentang heart rate monitoring system using finger tip thrgouh arduino and processing software [10].

Pada penelitian ini menggunakan sensor max 30100 sebagai sensor saturasi oksigen dalam darah dan juga sebagai sensor heart rate. Hasil dari pembacaan sensor akan diolah oleh mikrokontroller Arduino nano. Rangkaian untuk mengirim data pembacaan dari mikrokontroller ke smartsphone menggunakan ESP8266 ESP01 dengan komunikasi melalui wifi. Hasil pembacaan heart rate dan saturasi oksigen dapat di monitoring secara langsung dan kapanpu oleh perangkat smartphone.

\section{METODOLOGI PENELITIAN}

Pada metodologi penelitian yaitu membuat perangkat keras dan perangkat lunak. Rangkaian perangkat keras yaitu rangkaian catu daya, rangkaian interface dengan LCD Tft Nextion 3.5, rangkaian interface sensor max 30100, rangkaian ESP8266 ESP01 dan rangakaian arduino nano. Untuk perangkat lunak yaitu dengan menggunakan blynk. Diagram blok sistem ditampilkan pada Gambar 1. Diagram Blok Sistem berikut ini. 


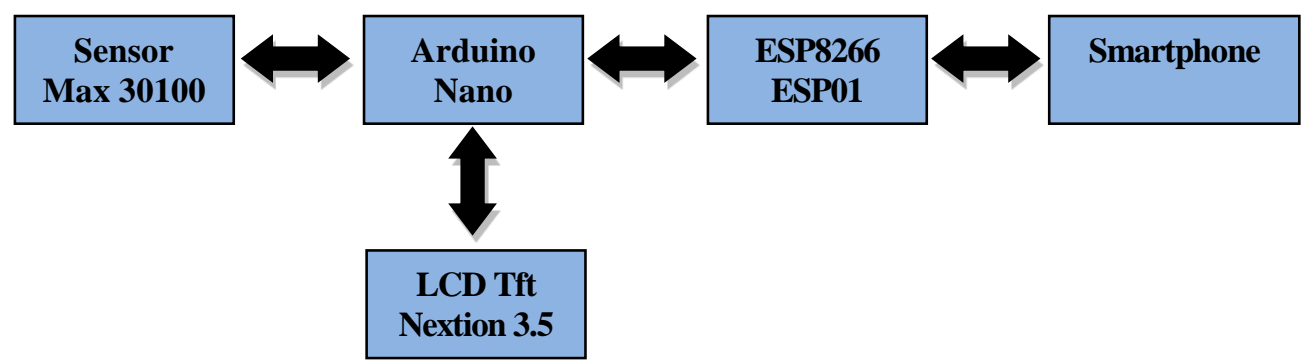

Gambar 1. Diagram Blok Sistem

Hasil monitoring yang dilakukan oleh smartphone berisikan hasil pembacaan heart rate dan saturasi oksigen yang dihasilkan dari pembacaan sensor max 30100 yang dibaca oleh mikrokontroller arduino Nano. Arduino Nano akan mengirimkan data pembacaan melalui perangkat ESP8266 ESP01 ke smartphone, sehingga smartphone dapat memonitoring secara langsung, kapanpun dan dimanapun. Rangkaian interface sensor max 30100 dengan mikrokontroller arduino nano seperti gambar 2.

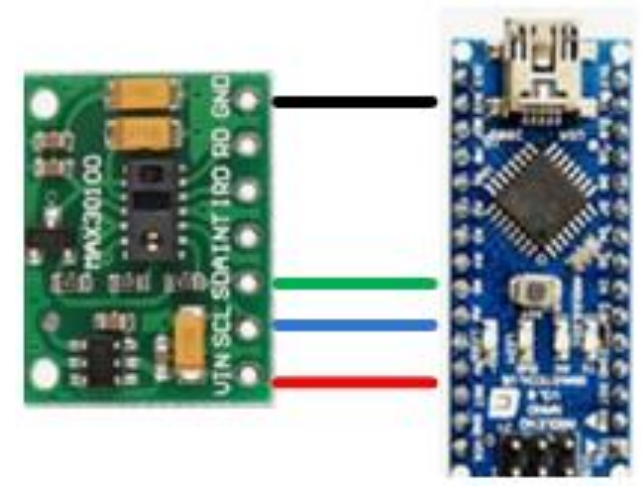

\section{Gambar 2. Rangkaian interface sensor max 30100}

Pada rangkaian gambar 2 diatas pembacaan sensor menggunakan komunikasi I2C yaitu komunikasi antar dua buah IC menggunakan pin SDA (Serial Data) dan SCL (Serial Clock). Tegangan yang digunakan pada sensor ini sebesar 5 volt. Pin SDA pada sensor dihubungkan pada pin A4 pada mikrokontroller Arduino Nano dan pin SCL sensor dihubungkan pada A5. Penggunaan SCL yaitu untuk mengontrol pengiriman data sensor ke mikrokontroller yang dikirimkan oleh sensor melalui SDA. Cara kerja sensor yaitu terdapat 2 led yang terdiri dari led merah dan IR (Infrared) photodetektor. Pendeteksi cahaya yang terdapat di masing-masing sisi probe menyebarkan cahaya melalui jaringan tubuh menuju ke pendeteksi cahaya. Cahaya inframerah terserap lebih banyak pada hemoglobin dengan kadar oksigen yang lebih, sedangkan pada hemoglobin yang tidak memiliki kadar oksigen akan menyerap cahaya merah. Setiap detiknya melakukan beberapa kali pengukuran untuk penyerapan cahaya relatif. Hasil dari pengukuran tersebut kemudian di proses pada mikrkontroller. Hasil dari pengukuran selama 3 detik akan diambil sebagai nilai rata-rata. Listing program yang digunakan mikrokontroller arduino nano untuk membaca hasil pembacaan heart rate dan saturasi oksigen seperti listing program dibawah ini.

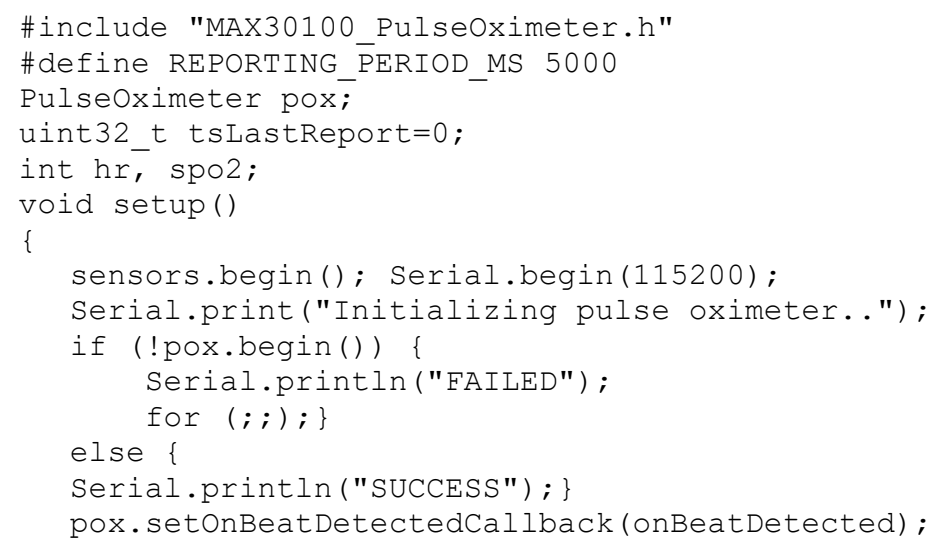




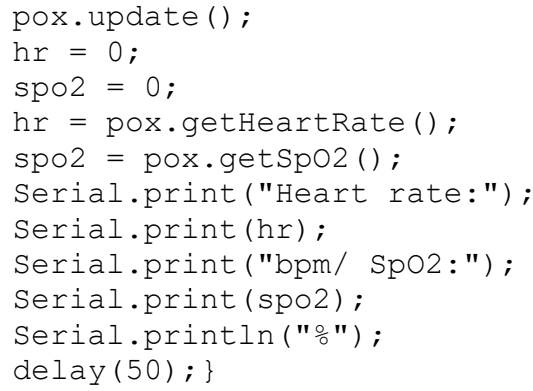

Data yang didapatkan dari sensor max 30100 akan dikirimkan mikrokontroller arduino nano melalui perangkat ESP8266 ESP01. Gambar rangkaian interface ditunjukan pada gambar 3. Rangkaian ESP8266 ESP01 dibawah ini.

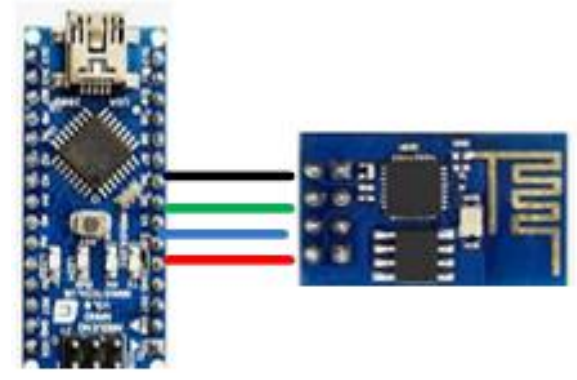

\section{Gambar 3. Rangkaian Interface ESP8266 ESP01}

Pada gambar rangkaian 3 diatas untuk mengirimkan data pembacaan heart rate dan saturasi oksigen menggunakan komunikasi serial yaitu Rx (reciver) dan Tx (Transmitter) dari ESP8266 ESP01 serta Tx dan Rx dari mikrokontroller arduino nano. Dimana Rx dari ESP8266 ESP01 terhubung dengan Tx dari mikrokontroller arduino nano dan sebalikanya Tx dari ESP8266 ESP01 terhubung dengan Rx dari mikrokontroller arduino nano. Pengiriman data dilakukan bergantian antara data heart rate dan saturasi oksigen. Data yang dikirim tersebut akan diteruskan oleh pemancar yang ada di ESP8266 ESP01 kepada smartphone yang telah tersambung melalui wifi. Listing program yang digunakan untuk mengirim data dari mikrokontroller arduino nano ke smartphone seperti dibawah ini.

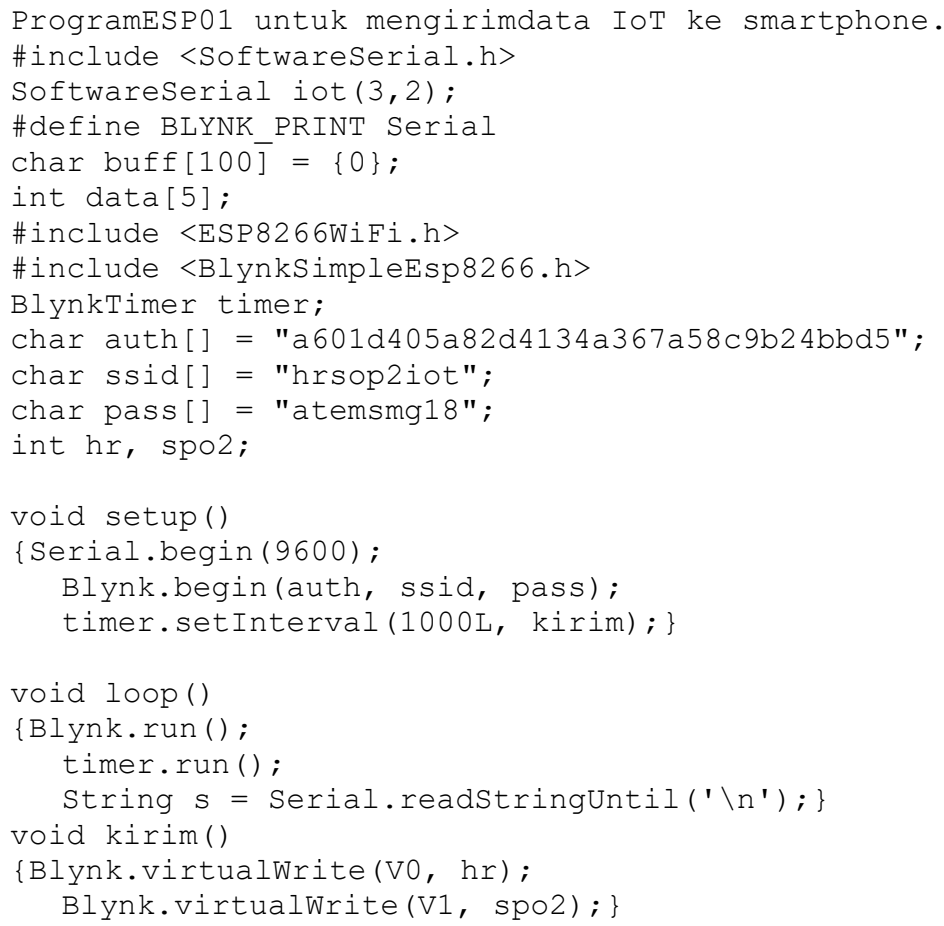


Selain data pembacan sensor dapat dikirimkan, data juga dapat dilihat secara langsung menggunakan LCD Tft Nextion 3.5. rangkaian interface LCD Tft Nextion 3.5 dengan mikrokontroller arduino nano seperti gambar 4. Rangakain interface LCD Tft Nextion 3.5 dibawah ini.

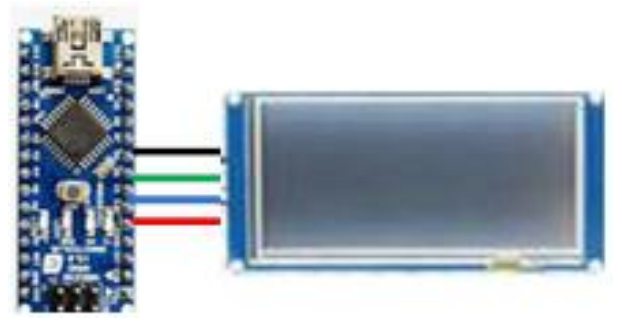

\section{Gambar 4. Rangkaian Interface LCD Tft Nextion 3.5}

Pada gambar 4. Rangkaian interface LCD Tft Nextion 3.5 komunikasi antara mikrokontroller arduino nano menggunakan komunikasi serial Rx (receiver) dan Tx (transmitter). Rx pada Lcd Nextion 3.5 dihubungkan pada pin D10 yang bersifat sebagai Tx pada mikrokontroller arduino nano, sebaliknya Tx pada Lcd Nextion 3.5 dihubungkan pada pin D11 yang bersifat sebagai Rx pada mikrokontroller arduino nano. Tampilan Lcd Nextion 3.5 bisa dirubah dengan menggunakan aplikasi nextion editor yang terdapat pada PC/Laptop. Pada Nextion editor tampilan dapat diedit antar komponen utama seperti tombol, teks, slider, panel instrumen, dll. Listing program menampilkan hasil pembacaan nilai heart rate dan saturasi oksigen seperti listing program dibawah ini.

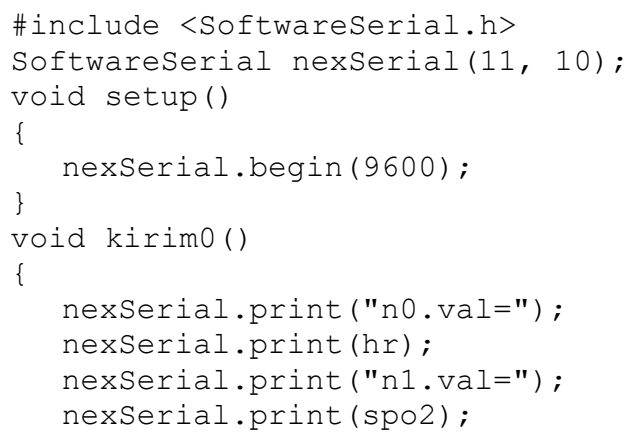

\section{HASIL PENELITIAN DAN PEMBAHASAN}

Pengukuran pembacaan heart rate dilakukan pada 3 responden dengan perbandingan pembacaan dengan peralatan pasien monitor. Adapun hasil dari perbandingan pengukuran dapat dilihat pada tabel 2 . Tabel pengukuran heart rate dibawah ini,

Tabel 2. Pengukuran heart rate

\begin{tabular}{|c|c|c|c|c|c|}
\hline No & Nama & LCD alat (bpm) & Blynk (bpm) & Pasien Monitor (bpm) & Selisih Pembacaan \% \\
\hline \multirow{3}{*}{1} & \multirow{3}{*}{ Agustin } & 85 & 85 & 85 & \multirow{3}{*}{$0.3 \%$} \\
\hline & & 88 & 88 & 86 & \\
\hline & & 89 & 91 & 90 & \\
\hline \multirow{3}{*}{2} & \multirow{3}{*}{ Fauzan } & 74 & 74 & 75 & \multirow{3}{*}{$0.8 \%$} \\
\hline & & 74 & 74 & 76 & \\
\hline & & 74 & 74 & 73 & \\
\hline \multirow{3}{*}{3} & \multirow{3}{*}{ Nova } & 71 & 71 & 70 & \multirow{3}{*}{$0.8 \%$} \\
\hline & & 69 & 69 & 67 & \\
\hline & & 69 & 69 & 70 & \\
\hline
\end{tabular}

Pada perbandingan sample heart rate antara pembacaan alat peneliti dengan pasien monitor didapatkan hasil persentase selisih terbesar yaitu 0,8\% dan presentasi terkecil sebesar 0,3\%, dimana prosentase kesalahan terbesar yaitu pada sample 2 dan 3 dengan Heart Rate rata - rata 74 bpm dan 69,9 bpm. Dimana perubahan heart rate tubuh manusia dapat dipengaruhi oleh pergerakan tangan, pengiriman data heart rate ke aplikasi blynk yang membutuhkan waktu kurang dari 1 menit tergantung dari koneksi jaringan internet. 
Pada pengukuran keluaran saturasi oksigen (SPO2) dilakukan sama seperti dengan pengukuran heart rate, yaitu dengan membandingkan pembacaan alat dengan pasien monitor. Untuk responden pengukuran sama seperti dengan pengukuran heart rate. Adapun hasil dari perbandingan pengukuran dapat dilihat pada tabel 2. Tabel pengukuran saturasi oksigen (SPO2),

Tabel 2. Pengukuran saturasi oksigen

\begin{tabular}{cccccc}
\hline No & Nama & LCD alat (\%) & Blynk (\%) & Pasien Monitor (\%) & Selisih Pembacaan (\%) \\
\hline \multirow{4}{*}{1} & \multirow{2}{*}{ Agustin } & 98 & 97 & 97 & $0 \%$ \\
& & 97 & 97 & 97 & \\
2 & \multirow{4}{*}{ Fauzan } & 97 & 97 & 97 & $1 \%$ \\
& & 97 & 97 & 98 & \\
& & 97 & 97 & 98 & $0.6 \%$ \\
& \multirow{2}{*}{ Nova } & 97 & 97 & 98 & \\
& & 97 & 97 & 97 & \\
\hline
\end{tabular}

Pada perbandingan sample pengukuran saturasi oksigen antara pembacaan alat peneliti dengan pasien monitor didapatkan hasil persentase selisih terbesar yaitu $1 \%$ dan presentasi terkecil sebesar $0 \%$, dimana prosentase kesalahan terbesar yaitu pada sample 2 dengan pembacaan saturasi oksigen rata - rata $97 \%$. Dimana perubahan saturasi oksigen di tubuh manusia dapat dipengaruhi oleh pergerakan tangan, kondisi saturasi oksigen tubuh yang dapat berubah disetiap saat, serta pengiriman data saturasi oksigen ke aplikasi blynk yang membutuhkan waktu kurang dari 1 menit tergantung dari koneksi jaringan internet.

\section{KESIMPULAN}

a) Selisih pembacaan nilai heart rate dan saturasi oksigen pada alat dan pasien monitor terbesar $0,8 \%$ untuk heart rate dan $1 \%$ untuk saturasi oksigen.

b) Pengiriman data hasil pembacaan sensor heart rate dan saturasi oksigen berhasil dimonitoring secara langsung melalui smartphone.

c) Pembacaan nilai heart rate dan saturasi oksigen yang berbeda antara tampilan di LCD dan Smarphone dikarenakan waktu pengiriman data pembacaan yang tidak sama.

\section{DAFTAR PUSTAKA}

[1] Tysinger E. How vital are vital signs? A systematic review of vital sign compliance and accuracy in nursing. J Sci Med. 2014.

[2] Fadillah H, Agustian I, Indriani A. Perancangan Alat Pemantau Detak Jantung, Resistansi Kulit dan Suhu Tubuh Jarak Jauh. 2015;5:1-6.

[3] Arthana IKR, Pradnyana IMA. Perancangan Alat Pendeteksi Detak Jantung Dan Notifikasi Melalui Sms. Semin Nas Ris Inov 2017. 2017.

[4] Utomo AS, Satrya AB, Tapparan Y. Monitoring Baby Incubator Sentral Dengan Komunikasi Wireless. Simetris J Tek Mesin, Elektro dan Ilmu Komput. 2018.

[5] Rozie F, Hadary F, W FTP, Nadi D, Berdasarkan B, Terkait P. Jumlah Denyut Nadi / Jantung Berbasis Android. 2014;1-10.

[6] Setiadi B S. Fakultas Teknik - Universitas Muria Kudus 153. Polsri. 2014;153-60.

[7] Prayogo I, Alfita R, Wibisono KA. Sistem Monitoring Denyut Jantung Dan Suhu Tubuh Sebagai Indikator Level Kesehatan Pasien Berbasis IoT ( Internet Of Thing ) Dengan Metode Fuzzy Logic Menggunakan Android. Triacs [Internet]. 2017;2:1-8. Tersedia pada: http://journal.trunojoyo.ac.id/triacs/article/view/3257.

[8] UGHI F. Proof-of-Concept Simulasi Kadar Saturasi Oksigen untuk Evaluasi Pulse Oximeter. ELKOMIKA J Tek Energi Elektr Tek Telekomun Tek Elektron. 2018;6(1):110.

[9] Yanuardhi R, Soegiarto D, Sularsa A. Rancang Bangun Pulse Oximetry Digital Berbasis Mikrokontroler Atmega16. eProceedings Appl Sci [Internet]. 2016;2(1):332-8. Tersedia pada: https://libraryeproceeding.telkomuniversity.ac.id/index.php/appliedscience/article/view/4083/3857.

[10] Mallick B, Patro AK. Heart Rate Monitoring System Using Finger Tip Through Arduino and Processing Software. Int J Sci Eng Technol Res. 2016. 